$\begin{array}{ll}\text { Research Square } & \begin{array}{l}\text { Preprints are preliminary reports that have not undergone peer review. } \\ \text { They should not be considered conclusive, used to inform clinical practice, } \\ \text { or referenced by the media as validated information. }\end{array}\end{array}$

\title{
Urbanization-gradient-, gender- and age-specific prevalence of metabolic syndrome abnormal components and their accumulation in adults in Burkina Faso: analysis of the first national data
}

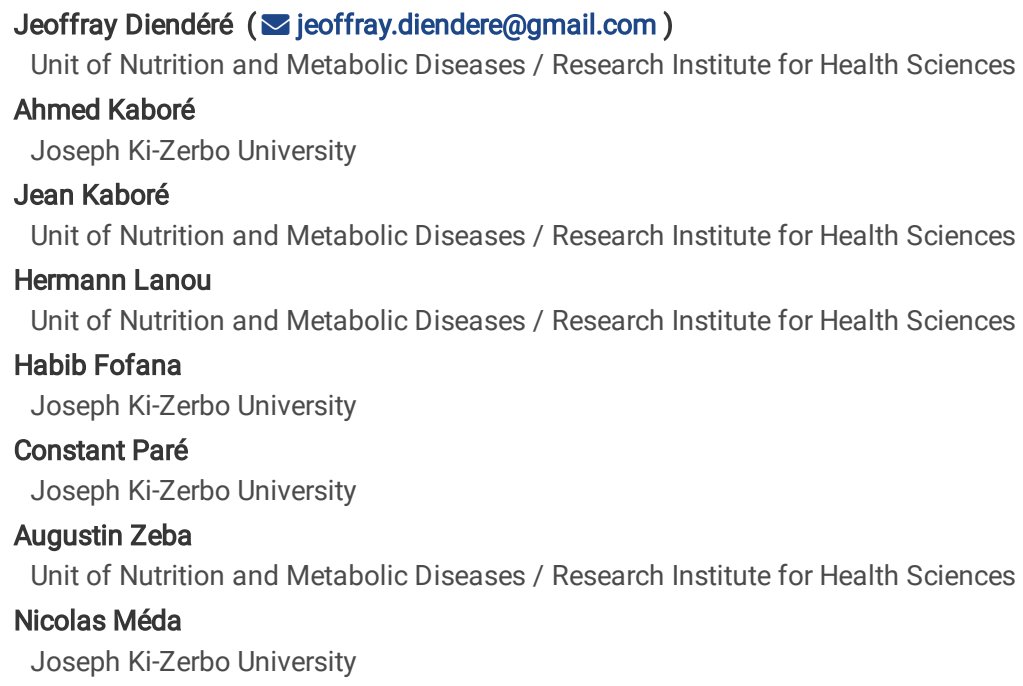




\section{Abstract}

Background: Accumulation of metabolic syndrome abnormal components dramatically increases the risk for cardiovascular diseases. This study aimed to assess the specific prevalence of abnormal components according to the urbanization gradient, gender and age, with the cumulative number of abnormalities in Burkinabè, using nationally representative data.

Methods: Data of 4365 participants to the Burkina Faso 2013 Stepwise approach to Surveillance study were analysed, including sociodemographic parameters (with age-groups of 25-34; 35-44; 45-54 and 55-64y), components defined with the International Diabetes Federation criteria (waist circumference [WC], blood pressure [BP], high-density lipoprotein cholesterol [HDL-C], fasting blood glucose [FBG]). The urbanization gradient was the four quartiles of the regional urbanization rates.

Results: Between quartiles, prevalences (\%) of abnormal components significantly differed and the extremes were: 71.1-81.2 in men ${ }^{(\mathbb{~})}, 75.9-81.2$ in women ${ }^{(囚)}$

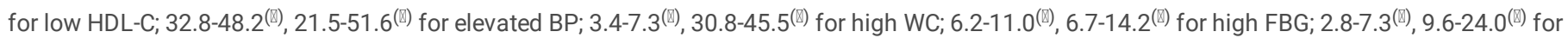

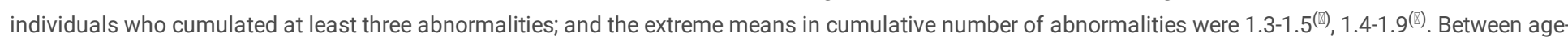

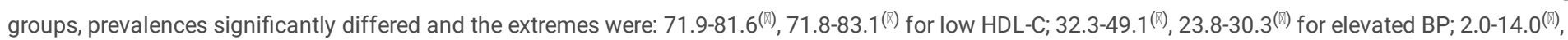

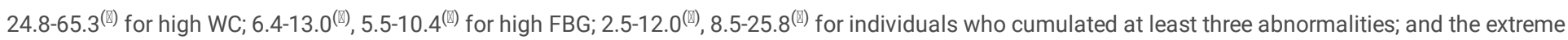
means in number of abnormalities were 1.2-1.4 $4^{(\mathbb{Z})}, 1.4-1.9^{(\mathbb{(})}$.

Conclusion: The low HDL-C was nationally prevalent and could serve as a background to the metabolic abnormalities' accumulation, which worsened with the process of urbanization and demographic transition, and more severely in women.

\section{Background}

Epidemiological transition in low and middle-income countries (LMICs) leads to new health challenges, such as the management of noncommunicable diseases (NCDs) ${ }^{(1,2)}$. Concerns with this transition were consistent with the gradual growth of the number of units of blood sugar ${ }^{(3)}$, blood pressure $(\mathrm{BP}){ }^{(4,5)}$ and lipid profile impairment ${ }^{(6-8)}$. Fat accumulation, specifically in the sub abdominal skin area with abdominal size change, could result from these physiological conditions ${ }^{(9,10)}$. Considered as a primary cardiovascular risk factor ${ }^{(11)}$, the metabolic syndrome (MetS) was specified by the International Diabetes Federation (IDF) with different components (high waist circumference [WC], elevated blood pressure [BP], high fasting blood glycemia [FBG], low level of blood high-density lipoprotein [HDL-C] and high level of triglyceridemia ${ }^{(12)}$ ). Accumulation of MetS abnormal components in individuals occurred over time, and because it was closely related to abnormal brachial ankle pulse wave velocity, it was analysed as an early indicator of arteriosclerosis ${ }^{(13,14)}$. From a Framingham study, the risk of developing cardiovascular diseases or diabetes in individuals who accumulated three or more metabolic abnormalities was very high (30-40\%) ${ }^{(15)}$. Moreover, each component may predict each other (reported in Sub-Saharan Africa [SSA], Benin ${ }^{(16)}$ ), or MetS state (reported in Ethiopia and South Africa) ${ }^{(17,18)}$, or the cardiovascular events ${ }^{(19,20)}$. Burden related-to-MetS is heavy ${ }^{(21,22)}$ and for a public health programme, the surveillance of components as well as their accumulation in individuals seems useful for cardiovascular diseases control. No previous study has been reported national prevalence of each component in Burkina Faso, a Sub-Saharan African (SSA) country. Data collected from the first national survey using Stepwise approach to Surveillance (STEPS) in Burkina Faso and relevant to MetS abnormal components (based on IDF criteria) were WC, BP, FBG and HDL-C. Our study aimed to assess the urbanization-gradient-specific as well as the gender- and age-specific prevalence of these components with their cumulative number in Burkina Faso.

\section{Methods}

\section{Variables of interest extracted from the STEPS database}

We used data from the Burkina Faso first national survey conducted in 2013 based on the STEPS method ${ }^{(23)}$

Participants' demographic variables included residence environment, gender, age, marital status, education level and occupation. Lifestyle factors were determined by using self-reporting techniques and included current (past month) alcohol consumption and current (past year) smoked/smokeless tobacco consumption. Anthropometric characteristics were WC $(\mathrm{cm})$, body mass index ([BMI] = weight $/ \mathrm{height}^{2}$, in $\mathrm{kg} / \mathrm{m}^{2}$ ) which was used to characterize underweight $\left(B M l<18.5 \mathrm{~kg} / \mathrm{m}^{2}\right)$, normal $\left(\mathrm{BMl}=18.5-24.9 \mathrm{~kg} / \mathrm{m}^{2}\right)$ overweight $\left(\mathrm{BMl}=25-29.9 \mathrm{~kg} / \mathrm{m}^{2}\right)$ and obesity $\left(\mathrm{BMl} \geq 30 \mathrm{~kg} / \mathrm{m}^{2}\right) \mathrm{states}$. The BP (in mmHg, which included systolic blood pressure [SBP] and diastolic blood pressure [DBP] values) was measured three times, and we kept only the mean value for each indicator. The biological characteristics tested in blood were TC ( $\mathrm{mmol} / \mathrm{l}), \mathrm{HDL}-\mathrm{C}(\mathrm{mmol} / \mathrm{l})$, and FBG (mmol/l). The IDF cut-offs were used to identity MetS abnormal components ${ }^{(12)}$ : (i) high WC when WC $\geq 95 / 80 \mathrm{~cm}$ for men/women, (ii) elevated BP when SBP/DBP $\geq 130 / 85 \mathrm{mmHg}$, (iii) FBG $\geq 5.6 \mathrm{mmol} / \mathrm{I}$ indicated high FBG, and (iv) HDL-C $<1.04 / 1.29 \mathrm{mmol} / \mathrm{I}$ for men/women indicated the Low HDL-C. The blood triglyceride was not available.

\section{Individuals included for analyses}

The nationwide representative sample size was calculated to be 4800 men and women aged $25-64$ years. The sample size calculation and the data collection processes throughout the country have been described ${ }^{(24,25)}$. We analysed variables for those with complete data for the sociodemographic, lifestyle, nutritional, biological and blood pressure parameters. Thus, we included 4365 individuals in the analyses. The Figure 1 presents the flowchart of those we studied.

\section{Categorization of Urbanization Gradient}


The geographical subdivision of the country population was carried out based on the level of urbanization for the 13 administrative regions (Figure 2). Urbanization gradient was characterized using the quartiles of the urbanization rates for regions provided by the "Institut National de la Statistique et de la Démographie INSD" in $2006^{(26,27)}$. The urbanization rate of each region was calculated as the proportion of inhabitants living in urban areas in the region. The national mean rate of urbanization was $23.3 \%$ [minimum $=6.6 \%$, maximum $=85.4 \%$, and the quartile cut-offs were $8.1,11.8$ and 19.3 . Thus, four administrative regions were included in the first quartile (Q1) or in the second quartile (Q2), three in the third quartile (Q3) and two (of the Regions of "Centre" and "Hauts-Bassins") in the fourth quartile (Q4) (Figure 2). The two Regions in Q4 included the political capital Ouagadougou ("Centre" Region) and the economic capital; Bobo-Dioulasso (in the Region of "Hauts-Bassins") and were the living areas for about $62 \%$ of the country urban dwellers (46.4\% for Ouagadougou, 15.4\% for Bobo-Dioulasso).

Statistical analyses: StataCorp Stata Statistical Software for Windows (Version 12.0, College Station, Texas, U.S.) was used to analyse the data. Quantitative variables were expressed in means \pm standard deviation, categorical variables as percentages (\%) with a confidence interval (Cl) of $95 \%$. When appropriate, Student's t or ANOVA tests were used to compare quantitative variables, $\chi 2$ or Fishers tests for categorical variables and a $p$-value $<0.05$ was considered statistically significant.

Ethical considerations: The study was conducted according to the guidelines laid down in the Declaration of Helsinki and all procedures involving human subjects/patients and the protocol of the STEPS survey was approved by the Ethics Committee for Health Research of the Ministry of Health (deliberation No: 2012-12092; December 05, 2012). Written informed consent was systematically recorded from each participant to STEPS survey.

\section{Results}

The sociodemographic factors are summarized in Table 1. In rural and urban areas, tobacco consumers were $22.1 \%$ and $13.1 \%$ respectively. Alcohol consumers were $26.9 \%$ in rural and $31.6 \%$ in urban areas, whereas $9.3 \%$ and $6.8 \%$ were both tobacco- $\&$-alcohol consumers, respectively.

Table 1: Sociodemographic and lifestyle features in the study sample $(n=4365)$ 


\begin{tabular}{|c|c|c|c|c|c|c|c|}
\hline \multirow[t]{3}{*}{ Parameters } & & & \multicolumn{5}{|c|}{ Gender } \\
\hline & \multicolumn{2}{|c|}{ Overall, $\mathrm{n}=4365$} & \multicolumn{2}{|c|}{ Male, $n=2164$} & \multicolumn{2}{|c|}{ Female, $n=2201$} & \multirow[b]{2}{*}{ p-value } \\
\hline & $\mathbf{n}$ & $\%$ & $\mathbf{n}$ & $\%$ & $\mathbf{n}$ & $\%$ & \\
\hline Age range (in years) & & & & & & & $* * *$ \\
\hline 1. $25-34$ & 1915 & 43.9 & 900 & 41.6 & 1015 & 46.1 & \\
\hline 1. $35-44$ & 1110 & 25.4 & 549 & 25.4 & 561 & 25.5 & \\
\hline 1. $45-54$ & 814 & 18.7 & 414 & 19.1 & 400 & 18.2 & \\
\hline 1. $55-64$ & 526 & 12.0 & 301 & 13.9 & 225 & 10.2 & \\
\hline Residence area & & & & & & & NS \\
\hline 1. Rural area & 3500 & 80.2 & 1761 & 81.4 & 1739 & 79.0 & \\
\hline 1. Urban area & 865 & 19.8 & 403 & 18.6 & 462 & 21.0 & \\
\hline Living area by urbanization gradient & & & & & & & NS \\
\hline 1. Q1 (first quartile) & 870 & 19.9 & 435 & 20.1 & 435 & 19.8 & \\
\hline 1. Q2 (second quartile) & 1238 & 28.4 & 642 & 29.7 & 596 & 27.1 & \\
\hline 1. Q3 (third quartile) & 1276 & 29.2 & 610 & 28.2 & 666 & 30.2 & \\
\hline 1. Q4 (fourth quartile) & 981 & 22.5 & 477 & 22.0 & 504 & 22.9 & \\
\hline Marital status & & & & & & & $*$ \\
\hline 1. Married or cohabitating & 3752 & 86.0 & 1833 & 84.7 & 1919 & 87.2 & \\
\hline 1. Singles & 613 & 14.0 & 331 & 15.3 & 282 & 12.8 & \\
\hline Education level & & & & & & & $* * *$ \\
\hline 1. No formal education & 3386 & 77.6 & 1590 & 18.1 & 1796 & 81.6 & \\
\hline 1. Primary school & 671 & 15.4 & 391 & 73.5 & 280 & 12.7 & \\
\hline 1. Secondary school and more & 308 & 7.0 & 183 & 8.4 & 125 & 5.68 & \\
\hline Occupation & & & & & & & $* * *$ \\
\hline 1. Self-employed/independent workers & 3056 & 70.0 & 1894 & 87.5 & 1162 & 52.8 & \\
\hline 1. Household-keepers & 933 & 21.4 & 13 & 0.6 & 920 & 41.8 & \\
\hline 1. Wage earner (in public or private field) & 240 & 5.5 & 174 & 8.0 & 66 & 3.0 & \\
\hline 1. Jobless & 136 & 3.1 & 83 & 3.8 & 53 & 2.4 & \\
\hline Current tobacco use: yes & 887 & 20.3 & 638 & 29.5 & 249 & 11.3 & $* * *$ \\
\hline Current alcohol use: yes & 1216 & 27.9 & 668 & 30.9 & 548 & 24.9 & $* * *$ \\
\hline Current concomitant tobacco and alcohol use: yes & 383 & 8.8 & 271 & 12.5 & 112 & 5.1 & $* * *$ \\
\hline
\end{tabular}

NS: Not significant, *: indicates $\mathrm{P}<0 \bullet 05, * *$ : indicates $\mathrm{P}<0 \bullet 01, * * *$ : indicates $\mathrm{P}<0 \bullet 001$

Figures 3 \& 4 show the change in the prevalence of abnormal components respectively with regard to the quartiles of the urbanization and the four age-groups in each gender, while Figure 5 reports the pattern for those who cumulated at least three abnormal components. The Supplemental Table specifies means of parameters used to characterize MetS components, and the prevalence of abnormal components according to quartiles of urbanization rates and age-groups for each gender. Between quartiles, prevalences (\%) of abnormal components significantly differed, and the extremes were: 71.1-81.2 in men ${ }^{(囚)}$, 75.9-81.2 in

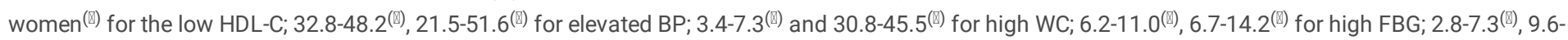
$24.0^{(\mathbb{X})}$ for those with at least three abnormal components. The change in the prevalences consisted in the significant and gradual increases from Q1 to Q4 concerning high WC in women, high FBG in both sexes and cumulating at least three abnormal components in both sexes (Figures 3A, 3C, 5A \& Supplemental Table). 


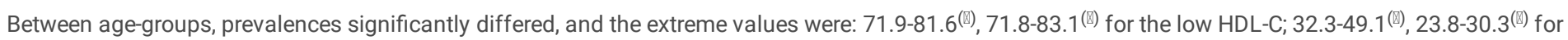

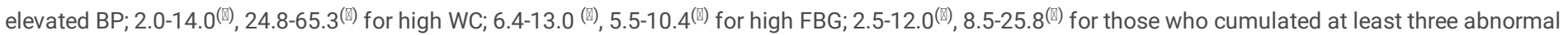
components. The change in the prevalences consisted in the significant and gradual increases from the youngest (25-34y) to oldest (55-64y) age-groups concerning high WC in both sexes, elevated BP in both sexes, high FBG in both sexes and cumulating at least three components for female gender (Figures 4A, 4B, 4C, 5B \& Supplemental Table).

On the opposite, the prevalence of low HDL-C gradually decreased, especially in men, from Q1 to Q4, as from the youngest to oldest age-groups (Figures 3D, 4D \& Supplemental Table).

Table 2 describes the means number of abnormal components across quartiles and age-groups: In the quartiles, the extreme means in cumulative number of

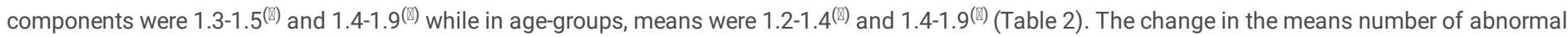
components consisted in the significant and gradual increases from Q1 to Q4, as well as the youngest to oldest age-groups in both sexes (Table 2). Within any age-group (except in the youngest), the prevalence of those with either two components or three components were higher in female gender, which also had the higher prevalence of individuals who cumulated three components within each quartile (Table 2).

Table 2: In men/women, prevalence of those without abnormal component, or with one, two, three or four cumulative abnormal components according to the age-group or the urbanization gradient $(\mathrm{n}=4365)$

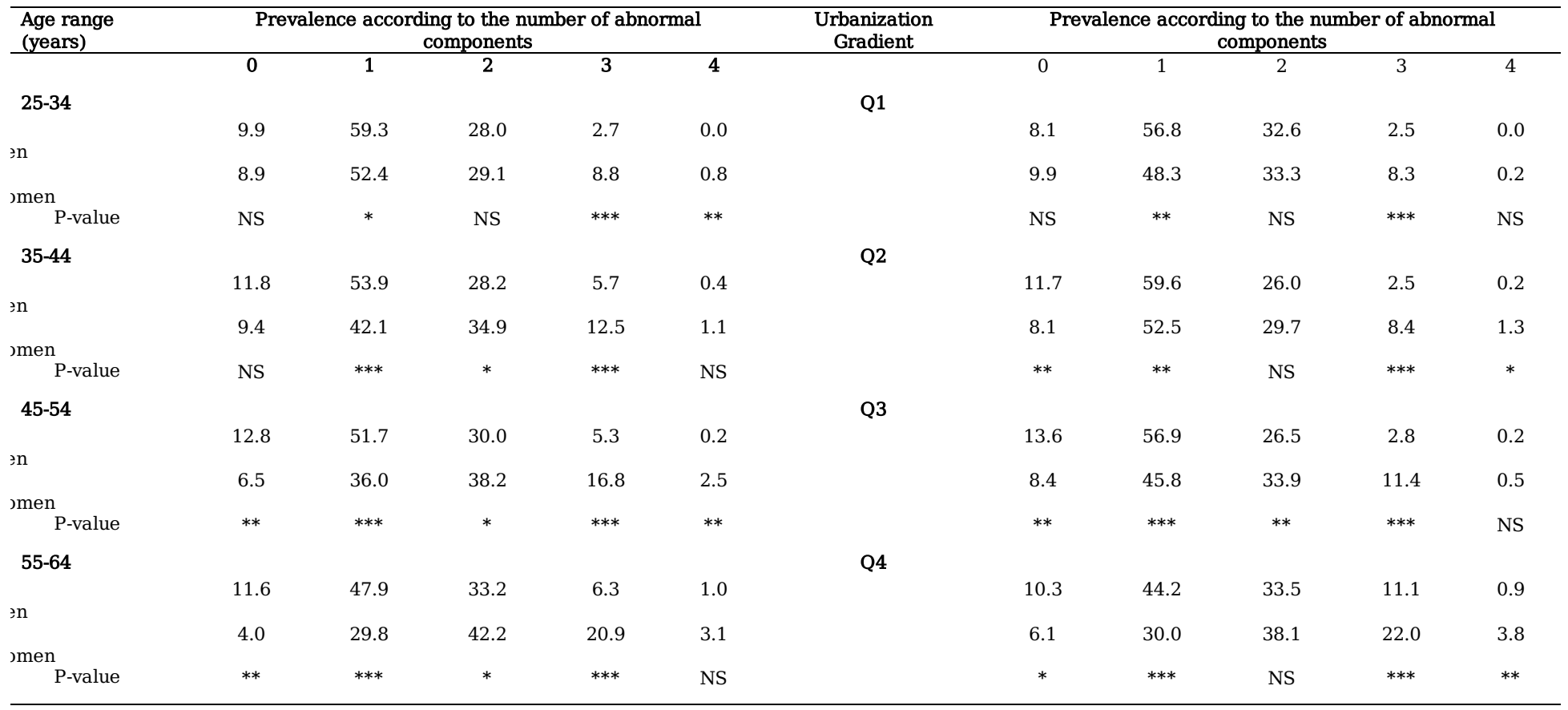

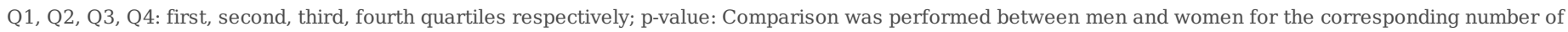
abnormal components in column. NS: Not significant, *: indicates $\mathrm{P}<0 \bullet 05$, **: indicates $\mathrm{P}<0 \bullet 01, * * *$ : indicates $\mathrm{P}<0 \bullet 001$

Table 3 reports prevalence of abnormal components according to the BMI categories, tobacco and/or alcohol consumption: For high WC, elevated BP or cumulating at least three components, prevalences progressively grew with the ascending BMI categories $\left(<18.5,18.5-25,25-30, a n d \geq 30 \mathrm{~kg} / \mathrm{m}^{2}\right)$. In concomitant tobacco-\&-alcohol consumers, prevalence of high WC, elevated BP, low HDL-C and that of individuals who cumulated at least three abnormal components were lower (Table 3).

Table 3: Overall prevalence of MetS abnormal components according to the BMI categories and the lifestyle features ( $\mathrm{n}=4365$ )

\begin{tabular}{|c|c|c|c|c|c|c|c|c|c|c|c|c|c|c|c|c|c|c|c|c|c|c|}
\hline \multirow[t]{3}{*}{$\begin{array}{c}\text { Abnormal } \\
\text { component }\end{array}$} & \multicolumn{9}{|c|}{ Nutritional status } & \multicolumn{5}{|c|}{ Tobacco use } & \multicolumn{5}{|c|}{ Alcohol use } & \multicolumn{3}{|c|}{$\begin{array}{r}\text { Concomitant toba } \\
\text { use }\end{array}$} \\
\hline & $\begin{array}{r}\text { Unde } \\
\mathrm{n}\end{array}$ & $\begin{array}{l}\text { rweight, } \\
=492\end{array}$ & $\begin{array}{l}\text { No } \\
\mathrm{n}=\end{array}$ & $\begin{array}{l}\text { mal, } \\
3110\end{array}$ & $\begin{array}{c}\text { Over } \\
\mathrm{n}=\end{array}$ & $\begin{array}{l}\text { veight, } \\
575\end{array}$ & $\begin{array}{c}\mathrm{Ob} \\
\mathrm{n}=\end{array}$ & $\begin{array}{l}\text { sity, } \\
188\end{array}$ & $\begin{array}{c}\mathrm{P}- \\
\text { value }\end{array}$ & $\mathrm{n}=$ & $\begin{array}{l}0, \\
478\end{array}$ & Yes, & $\mathrm{A}=887$ & $\begin{array}{c}\mathrm{p}- \\
\text { value }\end{array}$ & $\mathrm{n}=$ & $\begin{array}{l}0, \\
149\end{array}$ & & $\begin{array}{l}\text { es, } \\
1216\end{array}$ & $\begin{array}{c}\mathrm{p}- \\
\text { value }\end{array}$ & $\mathrm{n}=$ & $\begin{array}{l}0, \\
982\end{array}$ & Yes, \\
\hline & $\%$ & $\begin{array}{c}95 \% \\
\text { CI }\end{array}$ & $\%$ & $\begin{array}{c}95 \% \\
\text { CI }\end{array}$ & $\%$ & $\begin{array}{c}95 \% \\
\text { CI }\end{array}$ & $\%$ & $\begin{array}{c}95 \% \\
\text { CI }\end{array}$ & & $\%$ & $\begin{array}{c}95 \% \\
\mathrm{CI}\end{array}$ & $\%$ & $\begin{array}{c}95 \% \\
\text { CI }\end{array}$ & & $\%$ & $\begin{array}{c}95 \% \\
\text { CI }\end{array}$ & $\%$ & $\begin{array}{c}95 \% \\
\text { CI }\end{array}$ & & $\%$ & $\begin{array}{c}95 \% \\
\text { CI }\end{array}$ & $\%$ \\
\hline High WC & 6.3 & $4.3-8.8$ & 13.5 & $\begin{array}{l}12.3- \\
14.8\end{array}$ & 54.6 & $\begin{array}{l}50.4- \\
58.7\end{array}$ & 86.7 & $\begin{array}{l}81.0- \\
91.2\end{array}$ & $* * *$ & 24.1 & $\begin{array}{l}22.7- \\
25.6\end{array}$ & 10.2 & $\begin{array}{l}8.2- \\
12.3\end{array}$ & $* * *$ & 21.9 & $\begin{array}{l}20.4- \\
23.4\end{array}$ & 19.7 & $\begin{array}{l}17.5- \\
22.1\end{array}$ & 0.12 & 22.2 & $\begin{array}{l}21.0- \\
23.6\end{array}$ & 11.2 \\
\hline $\begin{array}{l}\text { Elevated } \\
\text { BP }\end{array}$ & 28.7 & $\begin{array}{l}24.7- \\
32.9\end{array}$ & 30.9 & $\begin{array}{l}29.3- \\
32.6\end{array}$ & 45.4 & $\begin{array}{l}41.3- \\
49.6\end{array}$ & 59.6 & $\begin{array}{l}52.2- \\
66.6\end{array}$ & $* * *$ & 34.0 & $\begin{array}{l}32.5- \\
35.6\end{array}$ & 32.9 & $\begin{array}{l}29.8- \\
36.1\end{array}$ & NS & 32.3 & $\begin{array}{l}30.7- \\
34.0\end{array}$ & 37.8 & $\begin{array}{l}35.0- \\
40.5\end{array}$ & $* * *$ & 33.4 & $\begin{array}{l}31.9- \\
34.9\end{array}$ & 38.4 \\
\hline High FBG & 9.6 & $\begin{array}{r}7.1- \\
12.5\end{array}$ & 7.6 & $\begin{array}{l}6.7- \\
8.5\end{array}$ & 11.0 & $\begin{array}{l}8.5- \\
13.8\end{array}$ & 15.4 & $\begin{array}{l}10.6- \\
21.4\end{array}$ & $* * *$ & 8.7 & $\begin{array}{l}7.7- \\
9.6\end{array}$ & 8.2 & $\begin{array}{c}6.5- \\
10.2\end{array}$ & NS & 7.8 & $\begin{array}{l}6.9- \\
8.8\end{array}$ & 10.5 & $\begin{array}{l}8.9- \\
12.4\end{array}$ & $* *$ & 8.3 & $\begin{array}{l}7.5- \\
9.2\end{array}$ & 11.0 \\
\hline Low HDL-C & 80.9 & $\begin{array}{l}77.1- \\
84.3\end{array}$ & 77.4 & $\begin{array}{l}75.9- \\
78.9\end{array}$ & 75.0 & $\begin{array}{l}71.2- \\
78.4\end{array}$ & 80.3 & $\begin{array}{l}73.9- \\
85.7\end{array}$ & NS & 77.8 & $\begin{array}{c}76.4- \\
79.2\end{array}$ & 76.9 & $\begin{array}{l}74.0- \\
79.6\end{array}$ & NS & 80.1 & $\begin{array}{l}78.6- \\
81.5\end{array}$ & 71.2 & $\begin{array}{c}68.6- \\
73.7\end{array}$ & $* * *$ & 78.4 & $\begin{array}{l}77.1- \\
79.6\end{array}$ & 69.7 \\
\hline $\begin{array}{l}\text { Having at } \\
\text { least } 3 \\
\text { components }\end{array}$ & 3.2 & $1.9-5.2$ & 5.2 & $\begin{array}{c}4.4- \\
6.0\end{array}$ & 24.0 & $\begin{array}{l}20.6- \\
27.7\end{array}$ & 48.9 & $\begin{array}{l}41.6- \\
56.3\end{array}$ & $* * *$ & 10.3 & $\begin{array}{l}9.3- \\
11.4\end{array}$ & 5.5 & $\begin{array}{l}4.1- \\
7.2\end{array}$ & $* * *$ & 9.37 & $\begin{array}{c}8.4- \\
10.4\end{array}$ & 9.2 & $\begin{array}{l}7.6- \\
11.0\end{array}$ & NS & 9.6 & $\begin{array}{l}8.7- \\
10.6\end{array}$ & 6.0 \\
\hline
\end{tabular}




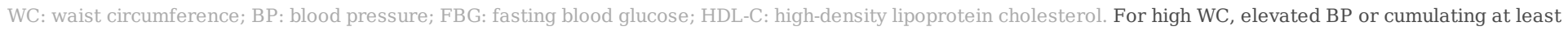

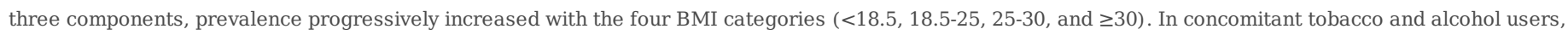

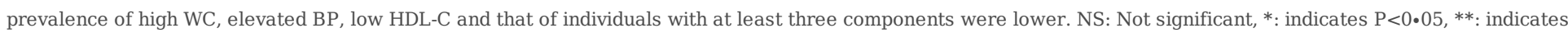
$\mathrm{P}<0 \bullet 01, * * *$ : indicates $\mathrm{P}<0 \bullet 001$

\section{Discussion}

The alarming finding was the high level of low HDL-C throughout the country. The means in number of components gradually increased from the lowest to highest urbanized settings, from the youngest to oldest age-groups, and the female gender frequently cumulated a great number of abnormal components.

\section{Low HDL-C}

Low HDL cholesterol was widespread in Burkina Faso (Figure 3D, 4D \& Supplemental Table) and suggests a vulnerability to the accumulation of abnormal components for great number of people. Since low HDL-C was (after abdominal obesity) strongly associated with either MetS or cardiovascular events in SSA (28), its magnitude in Burkina Faso supports its ranking among key health issues by the national Public Health system. The micronutrient deficiency was associated with low HDL-C which in turn was associated with either undernutrition or overweight/obesity in Benin SSA (16) and seems also valid for Burkina Faso. Indeed, underweight and overweight/obesity are a frequently occurring problem (respectively $11.3 \%$ and $17.5 \%$ ) and the prevalence of low HDL-C in undernourished (80.8\%) was identical to its level in obese (80.3\%, Table 4). Furthermore, in rural area where food availability is more problematic (29), a lower mean in HDL-C has been described $(0.9 \pm 0.5 \mathrm{vs} .1 .1 \pm 0.5 \mathrm{mmol} / \mathrm{l} ; \mathrm{p}=0.0001){ }^{(30)}$, and we reported a higher prevalence of low HDL-C in lower urbanized areas (Supplemental Table). Public health interventions for low HDL-C reduction should consider both undernutrition especially in a low urbanized area and overweight/obesity in a high urbanized area.

\section{High WC}

The pattern of high WC through the urbanization gradient also appears to be closely related to food availability in environment (marked by the urbanization gradient). The gradual decrease from highest quartile to the lowest one was observed (in females specifically) as its gradual decrease with decreasing BMl' categories (Figure 3A, Table 3 \& Supplemental Table).

Although food would be more available in a highly urbanized environment, this result suggests its nutritional use is inadequate ${ }^{(31)}$. The environment of consumers influences general with abdominal obesity occurrence, as reported in Brazil by de Freitas et al (32). The spectrum of the prevalence of Low HDL-C (gradual decrease inversely with the urbanization gradient especially in men) as that of high WC (especially in women), associated with its (high WC) overall pattern related to the BMI categories is compatible with the effect of the nutrition transition in LMICs, where accelerated urbanization induced change in lifestyle and dietary intake.

The wide gap in the prevalence of high WC between female and male gender at any age range (Figure 4A \& Supplemental Table) seemed to be driven by the IDF cut-offs used in our study (94/80 cm for men/women) that was criticized (as nonoptimal) in Central Africa (33). Since abdominal obesity was the primary determinant for MetS ${ }^{(34,35)}$ (in Cameroonian population, aOR reached 353.1; 95\% Cl:136.2-915.8; $p<0.001{ }^{(28)}$ ) and cardiovascular disease risk factors, specifying its cut-offs for SSA subjects was required ${ }^{(17,36)}$ for non-ambiguous prediction of risks considering the race-ethnicity-specificity ${ }^{(37)}$. The more shortened WC cut-offs of $81.2 / 81.0 \mathrm{~cm}$ for men/women were currently considered optimal in SSA ${ }^{(36)}$, and $80 / 94 \mathrm{~cm}^{(38) ; 80 / 75} \mathrm{~cm}{ }^{(39)}$ recommended respectively in Benin and Ghana. The specific thresholds for the Burkinabé population are not available and should be highlighted.

\section{High FBG}

In men as in women, the prevalence of high FBG increased with either urbanization gradient or age (Figures 3C, 4C \& Supplemental Table) The increase in glycemia with urbanization gradient (prevalence of diabetes was $0.8 \%, 3 \%$ and $6 \%$ for rural, rural-to-urban migrants, and urban Peruvians) ${ }^{(40)}$ has been identified. The age-specific change in prevalence of elevated FBG in both sexes (Figure 4C \& Supplemental Table) was closely to its spectrum reported among for both sexes in the age-groups of $18-45,46-55$ and $56-65$ years in China ${ }^{(41)}$. Moreover, since high FBG a prediabetes state reached $13.0 / 10.3 \%$ in men/women of Q4, and 11.0/14.2\% in those aged 55-64y (Supplemental Table) the epidemiological surveillance is required. As a low-income country (42), Burkina Faso is experiencing accelerated urbanization and rising life expectancy related to the demographic transition, which might support worsening in diabetes epidemiology.

\section{Elevated BP}

In both sexes, prevalence of elevated BP increased either with urbanization gradient or age (Figures 3B \& 4B and Supplemental Table). An increase in BP among urban residents (compared to rural or to semi-urban residents) was reported in Cameroonians ${ }^{(34)}$, as an age dependency of peripheral and central BPs $(43,44)$. The pattern in the age-specific change in prevalence of elevated BP among men (Figure 4B) was also closely to the spectrum reported by Jiang et al in China ${ }^{(41)}$. The overall prevalence of high BP (SBP/DBP $\geq 140 / 90 \mathrm{mmHg}$ or medication for hypertension) was low in Burkina Faso (18\%) ${ }^{(24)}$ but in Q4 and 55 64 age range, the respective prevalence of elevated BP in men/women reached $49.1 / 30.3 \%$ and $48.2 / 51.6 \%$. Thus, a cautious consideration for the lowness of hypertension level should be carefully done. In such conditions, the specific levels of BP components imply preventive interventions might be considered with regard to the urbanization and aging progress.

\section{Accumulation of MetS abnormal components}


From Q1 to Q4 as from the youngest to oldest age groups, the mean number of abnormal components significantly increased for both males (1.2 to 1.5) and females (1.4 to 1.9) (Table 2). In Nigerian communities, MetS (cumulating three among five components) progressively increased from rural (10\%), semi-urban $(18 \%)$ to urban $(35.1 \%)$ areas ${ }^{(45,46)}$ and female was more affected ${ }^{(46)}$. This trend was similar to our description concerning change in prevalence of individuals who cumulated at least three abnormal components, according to the urbanization gradient (Figure 5A \&Supplemental Table). The pattern in the age-specific change for the prevalence of individuals who cumulated at least three abnormal components in men/women (Figure 5B \& Supplemental Table) was closed to the spectrum of MetS prevalence described in men/women in Norway (basically urban) ${ }^{(47)}$, in the city of Oran in Algeria (48), in urban Ethiopia

${ }^{(49)}$, in the Black population of Cape town in South Africa ${ }^{(50)}$ and in the city of North-Western Nigeria ${ }^{(46)}$. Furthermore, the spectrum of individuals with at least three abnormal components in men mimicked that of elevated BP and high FGB (Figures 4B \& 4C \& 5B) as shown by Jiang et al, concerning MetS and raised $\mathrm{BP}$ and FBG in men ${ }^{(41)}$. Although the MetS prevalence was not provided in our study (triglyceride values were not available), its spectrum may be close to that of individuals with at least three abnormal components. In Q4 and 55-64 age range, their respective prevalence in men/women reached 12.0/25.8\% and 7.3/24.0\% (Supplemental Table). Because of its limited resources, the national health system should as a priority undertake a risk reduction approach concerning MetS and its abnormal components and women should be the primary target.

\section{Lifestyle factors and MetS abnormal components}

Lifestyle factors as tobacco and alcohol consumption whose level depends on the living environment ${ }^{(51,52)}$, may influence MetS components epidemiology

(53). Alcohol was more frequently used in urban area (31.6\%), whereas tobacco (22.1\%) or combined tobacco and alcohol (9.3\%) in rural area. The psychological expectancies related to these psychoactive substance consumptions may consist in quenching hunger when food was insufficiently intake or unavailable ${ }^{(54)}$ because ethanol and nicotine have an anti-appetite effect ${ }^{(55)}$. Tobacco or combined tobacco and alcohol may contribute to reduce food intake in most of rural people, while alcohol mainly contribute to increase HDL-C ${ }^{(56,57)}$ in urban dwellers. The prevalence of high WC was lower in tobacco consumers ( 10.2 vs $24.1 \%$ in nonusers; $p<0.001$ ) or in combined tobacco and alcohol consumers ( 11.2 vs $22.2 \%$ in non-consumers; $p<0.001)$ whereas that of low HDL-C was minored in alcohol consumers ( 71.2 vs $80.1 \%$ in non-consumers; $p<0.001$ ) (Table 3 ). The use of psychoactive substances should be taken into account when investigating prevalence of MetS and its abnormal components, and substantial variation was observed in the trend of individuals who cumulated at least three abnormal components (Table 3).

Limitations: Database does not include triglyceride values and thus, the cumulative number of components could not be specifically calculated and MetS could not be entirely defined.

\section{Conclusion}

Because of the urbanization and demographic transition processes in Burkina Faso, the current levels of MetS abnormal components and their accumulation in individuals should anticipate a worsening in the burden of cardiovascular diseases, that should be prevented, with women as the primary target.

\section{Declarations}

\section{Compliance with ethical standards}

\section{Funding: none}

\section{Conflict of interest: none}

Acknowledgements: The authors thank the Ministry of Health for providing them with the STEPS survey database, and M. Samuel Kaboré for the English Language support.

Ethical approval: "This study was conducted according to the guidelines laid down in the Declaration of Helsinki and all procedures involving research study participants were approved by the Ethics Committee for Health Research of the Ministry of Health (deliberation No: 2012-12092; December 05, 2012). Written informed consent was obtained from all subjects."

Availability of data: The database of the STEPS survey used for this manuscript is available at the Ministry of Health of Burkina Faso. It can be obtained by request.

\section{References}

1. Omran AR (1971) The epidemiologic transition. A theory of the epidemiology of population change. Milbank Mem Fund Q 49, 509-538.

2. Shiroya V, Neuhann F, Müller O, et al. (2019) Challenges in policy reforms for non-communicable diseases: the case of diabetes in Kenya. Glob Health Action 12, 1611243

3. Danaei G, Finucane MM, Lu Y, et al. (2011) National, regional, and global trends in fasting plasma glucose and diabetes prevalence since 1980: systematic analysis of health examination surveys and epidemiological studies with 370 country-years and $2 \cdot 7$ million participants. Lancet $378,31-40$.

4. Danaei G, Finucane MM, Lin JK, et al. (2011) National, regional, and global trends in systolic blood pressure since 1980: systematic analysis of health examination surveys and epidemiological studies with 786 country-years and 5.4 million participants. Lancet 377, 568-577.

5. Fezeu L, Kengne AP, Balkau B, et al. (2010) Ten-year change in blood pressure levels and prevalence of hypertension in urban and rural Cameroon. J Epidemiol Community Health 64, 360-365. 
6. Gupta R, Guptha S, Agrawal A, et al. (2008) Secular trends in cholesterol lipoproteins and triglycerides and prevalence of dyslipidemias in an urban Indian population. Lipids in Health and Disease 7, 40.

7. Carroll MD, Lacher DA, Sorlie PD, et al. (2005) Trends in Serum Lipids and Lipoproteins of Adults, 1960-2002. JAMA 294, $1773-1781$.

8. Sumner AE, Zhou J, Doumatey A, et al. (2010) Low HDL-cholesterol with normal triglyceride levels is the most common lipid pattern in West Africans and African Americans with Metabolic Syndrome: Implications for cardiovascular disease prevention. CVD Prevention and Control 5, 75-80.

9. Appel SJ, Harrell JS \& Davenport ML (2005) Central obesity, the metabolic syndrome, and plasminogen activator inhibitor-1 in young adults. J Am Acad Nurse Pract 17, 535-541.

10. Lovejoy JC, Smith SR \& Rood JC (2001) Comparison of Regional Fat Distribution and Health Risk Factors in Middle-Aged White and African American Women: The Healthy Transitions Study. Obes. Res. 9, 10-16.

11. Huang PL (2009) A comprehensive definition for metabolic syndrome. Dis Model Mech 2, 231-237.

12. Alberti KGMM, Zimmet P \& Shaw J (2006) Metabolic syndrome--a new world-wide definition. A Consensus Statement from the International Diabetes Federation. Diabet. Med. 23, 469-480.

13. Zhu WH, Chen LY, Lu CR, et al. (2018) [Association between the accumulation of metabolic syndrome abnormal components and arterial pulse wave velocity among adult individuals undergoing routine health examination]. Zhonghua Xin Xue Guan Bing Za Zhi 46, 810-817.

14. Chen L, Zhu W, Mai L, et al. (2015) The association of metabolic syndrome and its components with brachial-ankle pulse wave velocity in south China. Atherosclerosis 240, 345-350.

15. Wannamethee SG, Shaper AG, Lennon L, et al. (2005) Metabolic Syndrome vs Framingham Risk Score for Prediction of Coronary Heart Disease, Stroke, and Type 2 Diabetes Mellitus. Arch Intern Med 165, 2644-2650. American Medical Association.

16. Delisle H, Ntandou G, Sodjinou R, et al. (2013) At-risk serum cholesterol profile at both ends of the nutrition spectrum in West African adults? The Benin study. Nutrients 5, 1366-1383.

17. Omuse G, Maina D, Hoffman M, et al. (2017) Metabolic syndrome and its predictors in an urban population in Kenya: A cross sectional study. BMC Endocr Disord 17, 37.

18. Peer N, Steyn K \& Levitt N (2016) Differential obesity indices identify the metabolic syndrome in Black men and women in Cape Town: the CRIBSA study. J Public Health (Oxf) 38, 175-182.

19. Vishram JKK (2014) Prognostic interactions between cardiovascular risk factors. Dan Med J 61, B4892.

20. Dada AS, Ajayi DD, Areo PO, et al. (2016) Metabolic Syndrome and Framingham Risk Score: Observation from Screening of Low-Income Semi-Urban African Women. Medicines (Basel) 3.

21. Ford ES (2005) Risks for All-Cause Mortality, Cardiovascular Disease, and Diabetes Associated With the Metabolic Syndrome: A summary of the evidence. Diabetes Care 28, 1769-1778.

22. Mazloomzadeh S, Karami Zarandi F, Shoghli A, et al. (2019) Metabolic syndrome, its components and mortality: A population-based study. Med J Islam Repub Iran 33, 11.

23. Bonita R, Winkelmann R, Douglas KA, et al. (2003) The WHO Stepwise Approach to Surveillance (Steps) of Non-Communicable Disease Risk Factors. In Global Behavioral Risk Factor Surveillance, pp. 9-22 [McQueen DV, Puska P, editors]. Boston, MA: Springer US.

24. Soubeiga JK, Millogo T, Bicaba BW, et al. (2017) Prevalence and factors associated with hypertension in Burkina Faso: a countrywide cross-sectional study. BMC Public Health 17, 64.

25. Millogo T, Bicaba BW, Soubeiga JK, et al. (2018) Diabetes and abnormal glucose regulation in the adult population of Burkina Faso: prevalence and predictors. BMC Public Health 18, 350.

26. Institut National de la Statistique et de la Démographie (2009) Theme 2: Etat et structure de la population. http://www.insd.bf/n/contenu/enquetes_recensements/rgph-bf/themes_en_demographie/Theme2-Etat_et_structure_de_la_population.pdf (accessed August 2020).

27. Institut National de la Statistique et de la Démographie Recensement général de la population et de l'habitation au Burkina Faso (RGPH) en 2006. http://www.insd.bf/n/index.php/publications/18-les-publications/enquetes-et-recensments/141-recensement-general-de-la-population-et-de-l-habitationau-burkina-faso-rgph-en-2006 (accessed August 2020).

28. Marbou WJT \& Kuete V (2019) Prevalence of Metabolic Syndrome and Its Components in Bamboutos Division's Adults, West Region of Cameroon. Biomed Res Int 2019, 9676984.

29. Frongillo EA \& Nanama S (2006) Development and validation of an experience-based measure of household food insecurity within and across seasons in northern Burkina Faso. J. Nutr. 136, 1409S-1419S.

30. Diendéré J, Kaboré J, Somé JW, et al. (2019) Prevalence and factors associated with overweight and obesity among rural and urban women in Burkina Faso. Pan Afr Med J 34.

31. Josse AR, Jenkins DJA \& Kendall CWC (2008) Nutritional determinants of the metabolic syndrome. J Nutrigenet Nutrigenomics 1, $109-117$.

32. de Freitas PP, de Menezes MC \& Lopes ACS (2019) Consumer food environment and overweight. Nutrition 66, 108-114.

33. Longo-Mbenza B, Kasiam Lasi On'kin JB, Nge Okwe A, et al. (2011) The metabolic syndrome in a Congolese population and its implications for metabolic syndrome definitions. Diabetes Metab Syndr 5, 17-24.

34. Fezeu L, Balkau B, Kengne A-P, et al. (2007) Metabolic syndrome in a sub-Saharan African setting: central obesity may be the key determinant. Atherosclerosis 193, 70-76. 
35. Cameron AJ, Boyko EJ, Sicree RA, et al. (2008) Central Obesity as a Precursor to the Metabolic Syndrome in the AusDiab Study and Mauritius. Obesity.

36. Ekoru K, Murphy G a. V, Young EH, et al. (2017) Deriving an optimal threshold of waist circumference for detecting cardiometabolic risk in sub-Saharan Africa. Int J Obes (Lond).

37. Zhu S, Heymsfield SB, Toyoshima H, et al. (2005) Race-ethnicity-specific waist circumference cutoffs for identifying cardiovascular disease risk factors. Am. J. Clin. Nutr. 81, 409-415.

38. El Mabchour A, Delisle H, Vilgrain C, et al. (2015) Specific cut-off points for waist circumference and waist-to-height ratio as predictors of cardiometabolic risk in Black subjects: a cross-sectional study in Benin and Haiti. Diabetes Metab Syndr Obes 8, 513-523.

39. Owiredu WKBA, Osei-Yeboah J, Aryee C, et al. (2017) Gender Specific Predictive Performance and Optimal Threshold of Anthropometric Indices for the Prediction of Hypertension among a Ghanaian Population in Kumasi. AJMAH, 1-10.

40. Miranda JJ, Gilman RH \& Smeeth L (2011) Differences in cardiovascular risk factors in rural, urban and rural-to-urban migrants in Peru. Heart 97, 787796.

41. Jiang B, Zheng Y, Chen Y, et al. (2018) Age and gender-specific distribution of metabolic syndrome components in East China: role of hypertriglyceridemia in the SPECT-China study. Lipids Health Dis 17, 92.

42. Popkin BM (1999) Urbanization, Lifestyle Changes and the Nutrition Transition. World Development 27, 1905-1916.

43. Wojciechowska W, Stolarz-Skrzypek K, Tikhonoff V, et al. (2012) Age dependency of central and peripheral systolic blood pressures: Cross-sectional and longitudinal observations in European populations. Blood Press. 21, 58-68.

44. Li Y, Staessen JA, Sheng C-S, et al. (2012) Age dependency of peripheral and central systolic blood pressures: cross-sectional and longitudinal observations in a Chinese population. Hypertens. Res. 35, 115-122.

45. Ulasi II, ljoma CK \& Onodugo OD (2010) A community-based study of hypertension and cardio-metabolic syndrome in semi-urban and rural communities in Nigeria. BMC Health Serv Res 10, 71.

46. Sabir AA, Jimoh A, Iwuala SO, et al. (2016) Metabolic syndrome in urban city of North-Western Nigeria: prevalence and determinants. Pan Afr Med J 23.

47. Hildrum B, Mykletun A, Hole T, et al. (2007) Age-specific prevalence of the metabolic syndrome defined by the International Diabetes Federation and the National Cholesterol Education Program: the Norwegian HUNT 2 study. BMC Public Health 7, 220.

48. Houti L, Hamani-Medjaoui I, Lardjam-Hetraf SA, et al. (2016) Prevalence of Metabolic Syndrome and its Related Risk Factors in the City of Oran, Algeria: the ISOR Study. Ethn Dis 26, 99-106.

49. Kaduka LU, Kombe Y, Kenya E, et al. (2012) Prevalence of metabolic syndrome among an urban population in Kenya. Diabetes Care 35, 887-893.

50. Peer N, Lombard C, Steyn K, et al. (2015) High prevalence of metabolic syndrome in the Black population of Cape Town: The Cardiovascular Risk in Black South Africans (CRIBSA) study. Eur J Prev Cardiol 22, 1036-1042.

51. Taype-Rondan A, Bernabe-Ortiz A, Alvarado GF, et al. (2017) Smoking and heavy drinking patterns in rural, urban and rural-to-urban migrants: the PERU MIGRANT Study. BMC Public Health 17, 165.

52. Brathwaite R, Addo J, Kunst AE, et al. (2017) Smoking prevalence differs by location of residence among Ghanaians in Africa and Europe: The RODAM study. PLoS ONE 12, e0177291.

53. Kodaman N, Aldrich MC, Sobota R, et al. (2016) Cardiovascular Disease Risk Factors in Ghana during the Rural-to-Urban Transition: A Cross-Sectional Study. PLOS ONE 11, e0162753. Public Library of Science.

54. Etu ES, Gemeda DH \& Hussen MA (2017) Prevalence and factors that influence smokeless tobacco use among adults in pastoralist communities of Borena Zone, Ethiopia: mixed method study. Tob Induc Dis 15, 1.

55. Pilhatsch M, Scheuing H, Kroemer N, et al. (2014) Nicotine administration in healthy non-smokers reduces appetite but does not alter plasma ghrelin. Hum Psychopharmacol 29, 384-387.

56. Whitehead TP, Robinson D \& Allaway SL (1996) The effects of cigarette smoking and alcohol consumption on blood lipids: a dose-related study on men. Ann. Clin. Biochem. 33 ( Pt 2), 99-106.

57. Wu DM, Pai L, Sun PK, et al. (2001) Joint effects of alcohol consumption and cigarette smoking on atherogenic lipid and lipoprotein profiles: results from a study of Chinese male population in Taiwan. Eur. J. Epidemiol. 17, 629-635.

\section{Figures}


105 Not eligible or invalid data on gender

150 Pregnant women

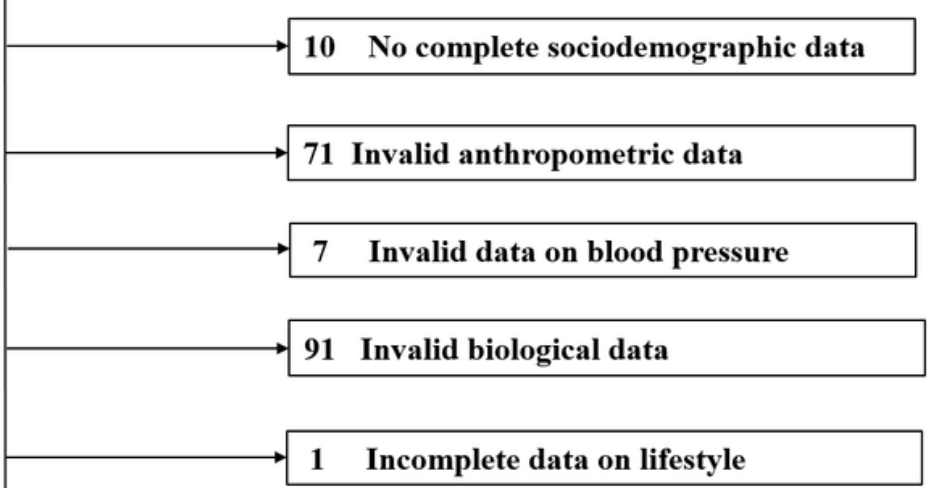

Men and women with complete data

4365

Figure 1

Flowchart of the study population.

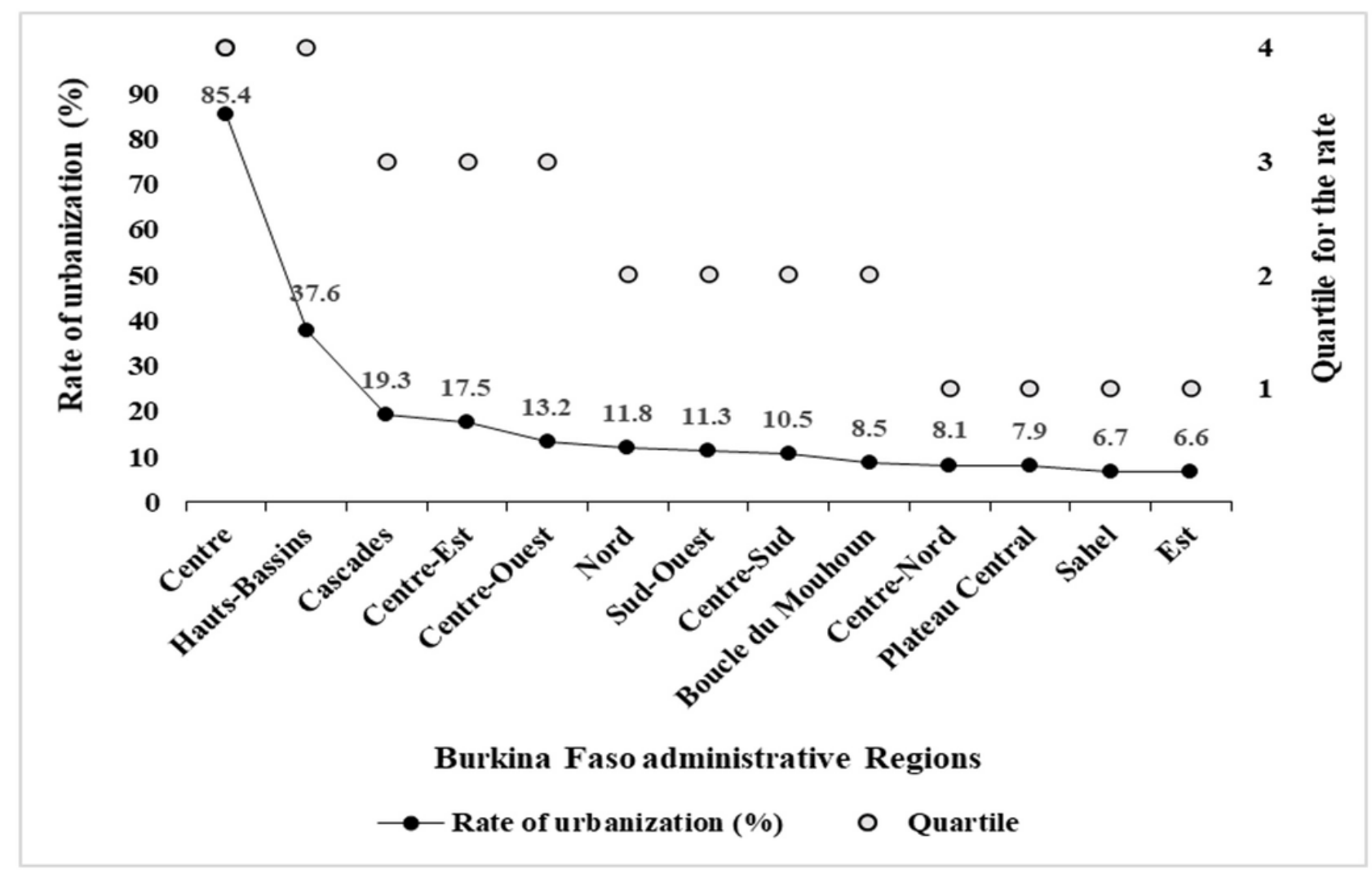

Figure 2 

quartiles were $8.1,11.8$ and $19.3 \%)$.
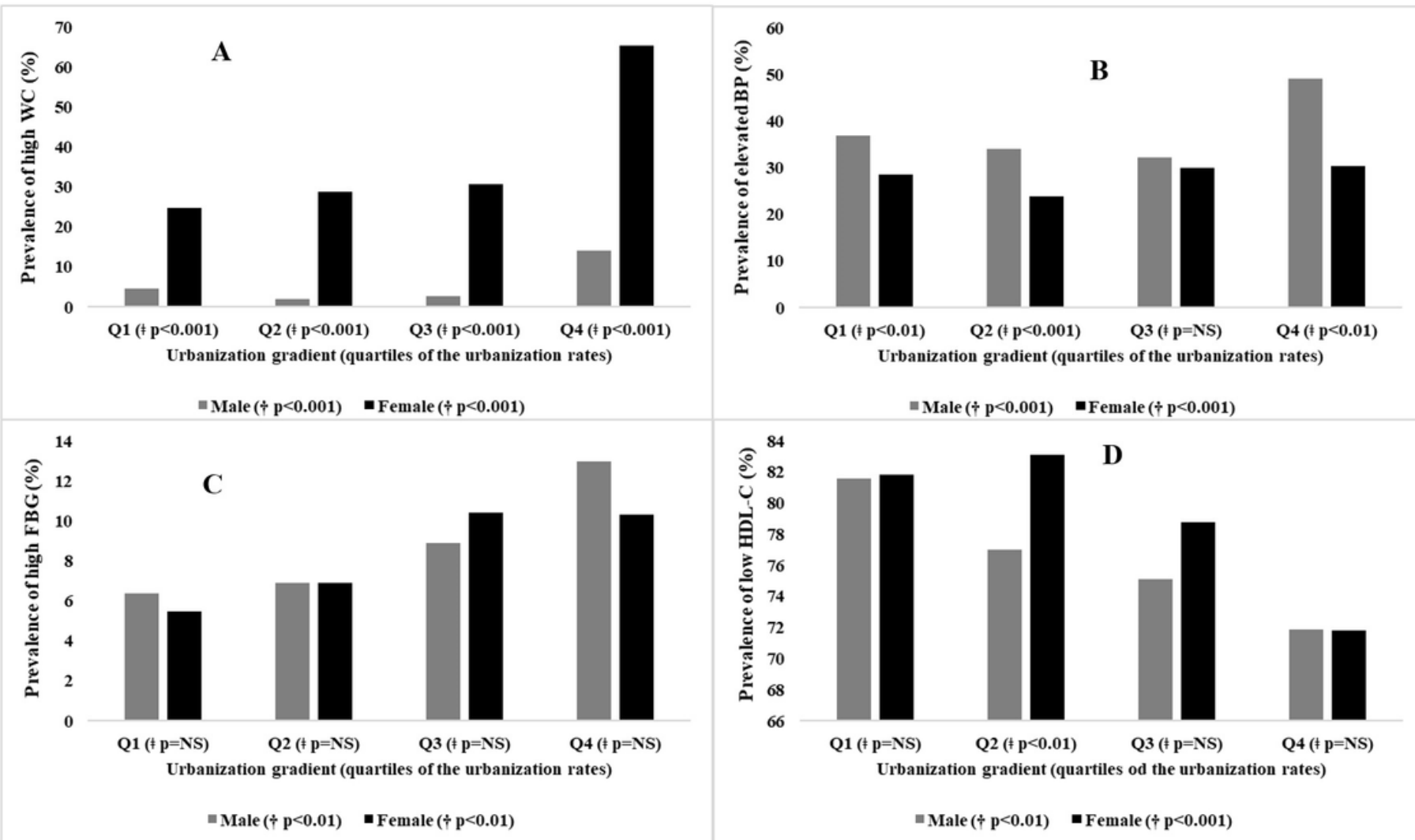

\section{Figure 3}

Prevalence of abnormal component (3A: high WC, 3B: elevated BP, 3C: high FBG, 3D: low HDL-C) according to the urbanization gradient, in men/women. WC: waist circumference, BP: blood pressure, FBG: fasting blood glucose, HDL-C: high-density lipoprotein cholesterol, p: P-value, NS: Not Significant. 邓p:

Comparison was performed between men and women within same quartile of the urbanization level; $† p$-value: Comparison was performed between the four quartiles in only men, or in only women. 


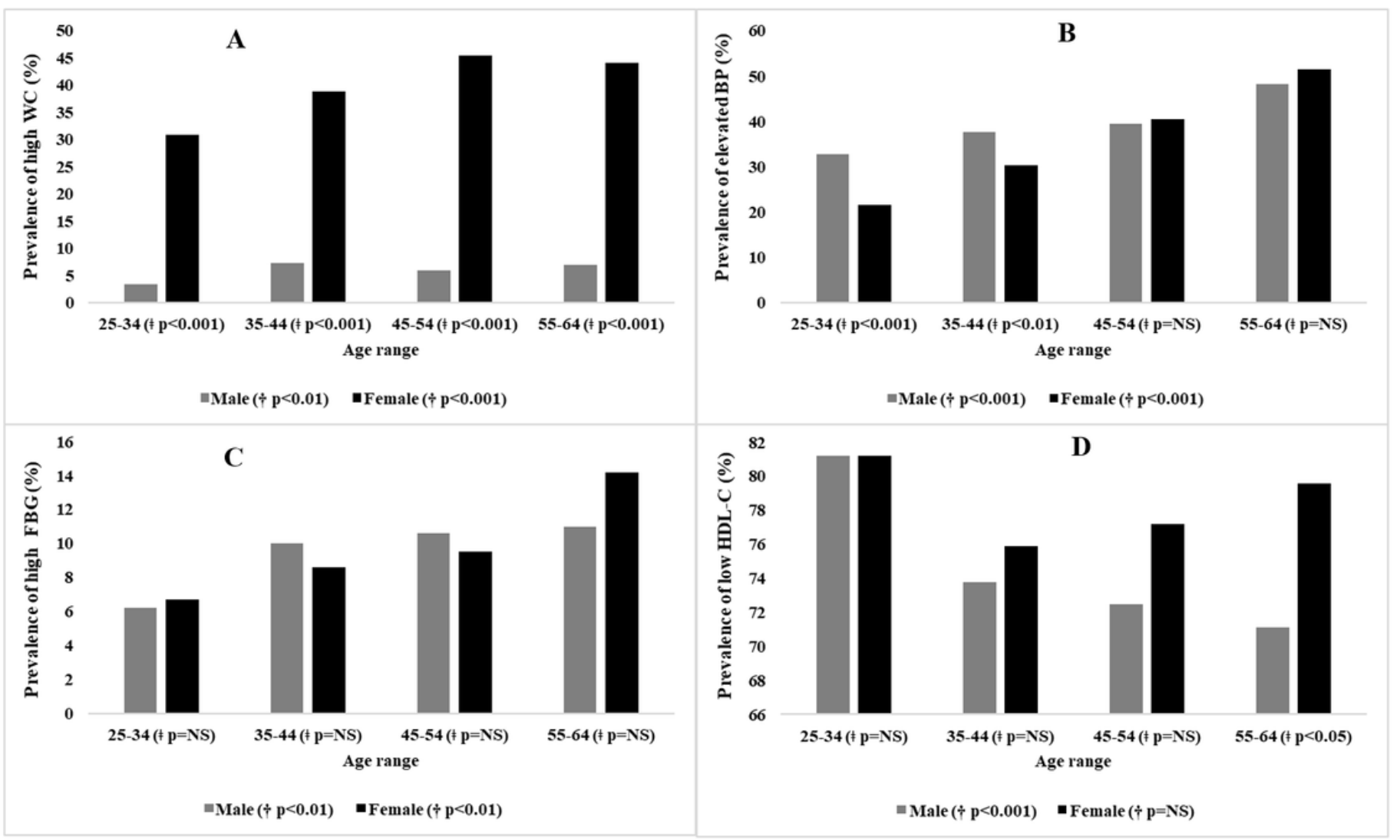

Figure 4

Prevalence of abnormal component (4A: high WC, 4B: elevated BP, 4C: high FBG, 4D: low HDL-C) according to the four age-groups, in men/women. WC: waist circumference, BP: blood pressure, FBG: fasting blood glucose, HDL-C: high-density lipoprotein cholesterol, p: P-value, NS: Not Significant. 邓p: Comparison was performed between men and women in the same age-group; $\uparrow p$-value: Comparison was performed between the four age-groups in only men, or in only women.

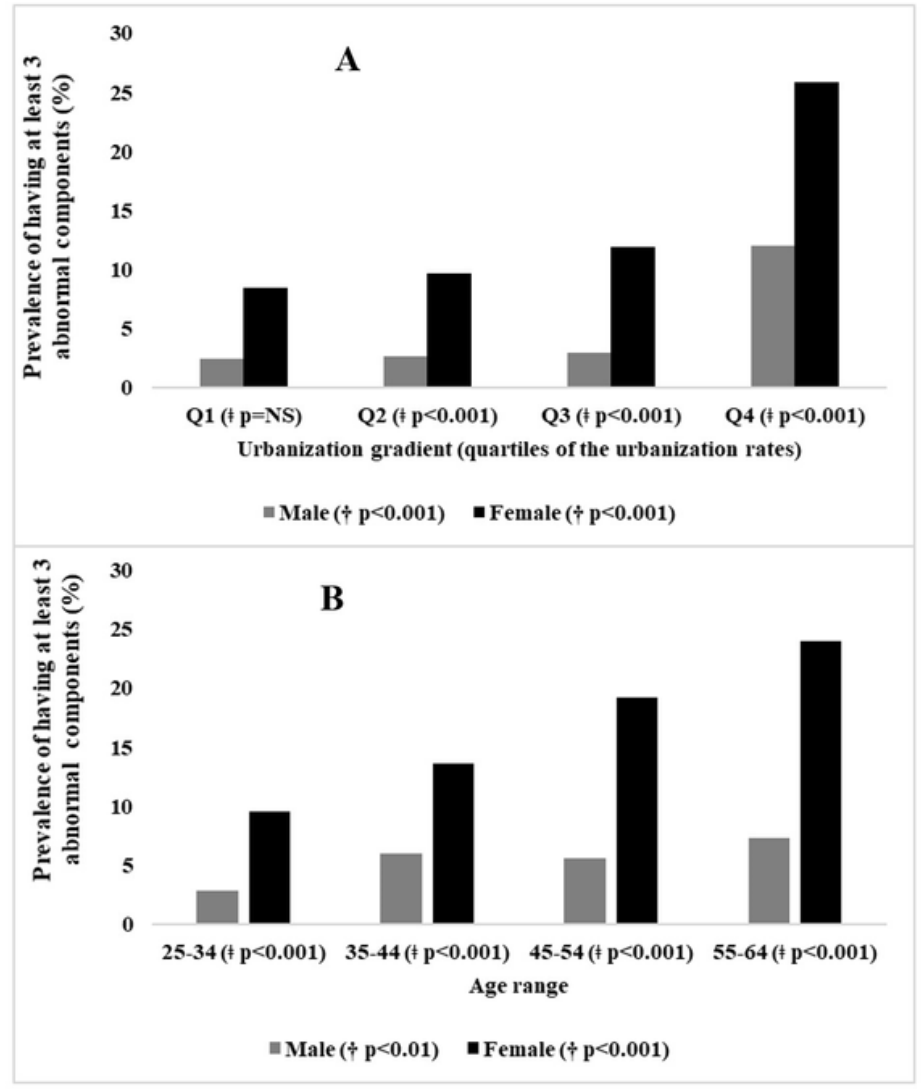

Figure 5 
Prevalence in men/women, of those with at least three abnormal components, in quartiles of urbanization level (5A); and in age-groups (5B). 『p: P-value when comparison was performed between men and women within the same age-group; $+p$ : P-value when comparison was performed between the four age-groups in only men, or in only women.

\section{Supplementary Files}

This is a list of supplementary files associated with this preprint. Click to download.

- SupplementaltableMetSComponentsPHN080920.docx 